\title{
Depression, Anxiety and Stress in Young Female Doctors is Associated with High Sexual Harassment Scores
}

Fatima Ali Raza Mughal', Hina Sharif, Arsalan Manzoor Mughal ${ }^{3}$, Ayesha Babar Kawish², Nazish Khan', Anila Rehman² 'Department of Community Medicine, Foundation University Medical College, Islamabad, ${ }^{2} \mathrm{Al}$-Shifa School of Public Health, Rawalpindi, 3Department of Anatomy, Rawalpindi Medical University, Rawalpindi, Pakistan.

\begin{abstract}
Background: Sexual harassment, a known cause of stress in females, makes them vulnerable to mental health issues and affects their professional performance. The objectives of the study were to assess the frequency of sexual harassment among female doctors based on age, designation, marital status, and household income, and to find out the association between sexual harassment and depression, anxiety, and stress in female doctors.

Methods: A cross-sectional study was conducted at three tertiary care hospitals of Rawalpindi. on $n=328$ female doctors including House officers, Post Graduate Trainees, Senior Registrars, Assistants, Associates and Full Professors. We used the Sexual Harassment Experience Questionnaire and the Depression, Anxiety and Stress Scale to assess sexual harassment and depression, anxiety and stress scores, $p$-value $<0.05$ was considered statistically significant.

Results: The mean age of 301 female doctors was $30.12 \pm 7.8$ years, equally represented from public and private hospitals. Mostly were married 154 (51.2\%), working as House Officers 126(41.9\%), The mean score on the Sexual Harassment Experience Questionnaire was $48.23 \pm 14.84$, with higher scores (52.83 \pm 16.2 ) in unmarried females ( $\leq 30$ years), working in junior levels in public sector hospitals $(p=0.001)$. A significant positive correlation (0.471) between the Sexual Harassment Experience Questionnaire and Depression Anxiety and Stress Scale scores was observed.
\end{abstract}

Conclusion: The incidences of sexual harassment were seen more in younger, unmarried junior female doctors. Higher Depression, Anxiety and Stress were found positively associated with higher Sexual Harassment scores. Hospitals should develop policies to protect female healthcare workers especially junior doctors, to minimize workplace sexual harassment negativity on mental health.

Keywords: Sexual Harassment; Depression; Anxiety; Female; Hospitals.

\section{Corresponding Author:}

\section{Dr. Fatima Ali Raza Mughal}

Department of Community Medicine,

Foundation University Medical College,

Islamabad, Pakistan.

Email: fatimaliraza@gmail.com

https://doi.org/10.36283/PJMD11-1/012

How to cite: Mughal FAR, Sharif H, Mughal AM, Kawish AB, Khan N, Rehman A. Depression, Anxiety and Stress in Young Female Doctors is Associated with High Sexual Harassment Scores. 2022; 1 1 (1): 72-77. doi: 10.36283/PJMD1 1-1/012 


\section{INTRODUCTION}

Sexual harassment at the workplace is "any behaviour characterized by the making of unwelcome and inappropriate sexual remarks or physical advances in a workplace or other professional or social situation" '. According to section 509 of the Pakistan Penal Code, sexual harassment is a criminal offense, because of which the offender can receive a sentence of imprisonment of three years in prison and a financial penalty of up to PKR $500,000^{2}$.

Sexual harassment is a known source of stress in nurses, which makes them vulnerable to mental health issues while also affecting their professional performance ${ }^{3}$. In $2016,26.9 \%$ of nurses from public sector hospitals of Lahore faced sexual violence mainly at the hands of male colleagues, patients and attendants ${ }^{4}$. According to the study of the University of Punjab significant positive correlation was found between sexual harassment at the workplace and symptoms of PTSD ${ }^{5}$.

Studies report that sexual harassment at the workplace is positively associated with mental health issues and contributes to depression and anxiety in the victims $s^{6,7}$. Therefore, it is evident that depression leads to reduced productivity at the workplace ${ }^{8}$. On a global level, things are hardly different. Studies from the US claim that sexual harassment of female doctors and discrimination against them is "rampantly" increasing?. An Australian study reported that post-graduate trainee doctors faced harassment by male colleagues as they are in a higher position of authority than them ${ }^{10}$. One study from Canada concluded that sexual harassment was one of the most common types of harassment faced by female doctors and was associated with negative mental health consequences such as burnout" ${ }^{1}$. Studies from Australia indicate that $29 \%$ of junior female doctors' experience harassment in the first two years of their residency ${ }^{2}$. A study from the Kingdom of Saudi Arabia studied the perceptions of doctors working in hospitals in KSA, $20.7 \%$ of female doctors under 30 years of age felt they experienced some form of sexual harassment at the hands of male doctors ${ }^{13}$.

However, what makes it a public health issue of considerable significance is that in a country like Pakistan, where there is already a dearth of practicing doctors with a density of physicians to the population of $7.8 / 10000$, sexual harassment is a cruel deterrent for female doctors joining the workforce ${ }^{14,15}$. A study from KPK indicated that $69.5 \%$ of nurses and $52.2 \%$ of female doctors experience some sort of sexual harassment at the workplace ${ }^{16}$. Although some work on the topic has been recorded in Pakistan, including that on nurses and in the banking sector, there is scant data from Rawalpindi regarding female doctors. The study aimed to find an association that exists between the workplace sexual harassment of female doctors and mental health issues, including depression, anxiety, and stress.

\section{METHODS}

A cross-sectional study was conducted at three tertiary care hospitals of Rawalpindi, two public sectors and one private sector, using non-probability convenience sampling over 06 months from June 2020 to November 2020. The sample size was calculated using OpenEpi software. Total $n=328$ samples, out of which 27 forms were incomplete and were not included in our data analysis. The female doctors including House officers, Post Graduate Trainees, Senior Registrars, Assistant, Associate and Full Professors working in tertiary care hospitals of Rawalpindi, who had held the same post for at least3 months were included in the study. Those not meeting the criteria or not wishing to participate were excluded.

Data was collected via both Google forms as well as in-person from lady doctors working in both public as well as private hospitals of Rawalpindi. Approval letters were obtained from the IRB/ERCs of the concerned institutions (Ref. No. 165/IREF/R$\mathrm{MU} / 2020$, No. MSPH-Thesis-Per/09-03) before the commencement of data collection. Informed consent was taken from each respondent before filling the form, both in the paper-based as well as Google forms version.

Respondents were assured of complete confidentiality. They were told that they could withdraw at any time without any fear of repercussion. They were also explained that neither they would not receive any compensation, monetary or otherwise, for their participation in this study. Writing the name was optional and the names that were given by the respondents were removed before analysis. The data given by the respondents remained with the primary investigator and was not shared with anyone else. The demographic information form contained the respondent's age, marital status, designation, whether the hospital is private or public sector, perceived sources of stress and monthly household income.

Data collection tools included a demographic information form, the Sexual Harassment Experience Questionnaire (SHEQ) and the Depression, Anxiety and Stress Scale (DASS). The SHEQ is a 35-item questionnaire that addresses workplace sexual harassment via 3 subscales including gender harassment ( 7 items), unwanted sexual attention ( 21 items) and sexual coercion (7 items). It uses a 4-point scale, the score on which ranges from 35 to 140 , a higher score signifying more frequent harassment experi- 
ences. The internal consistency coefficient for the SHEQ is 0.95 in total. All items of the SHEQ are determined empirically and had been assessed by specialists, hence there was adequate content validity. The respondents were asked to record only happening from the last 3 months.

DASS is a 42-item questionnaire by Lovibond and Lovibond, was used to measure depression (14 items), anxiety (14 items) and stress (14 items) among lady doctors. Each item is graded from 1-3. The total score ranges from 0 to 136. The scale has a Cronbach's alpha of 0.89. A study deems the validity of DASS as high. The respondents recorded happenings from the lastl week. Statistical Package for Social Sciences (SPSS) version 26 was used for entry and statistical analyses of data. Demographic information was reported as frequencies and percentages. Pearson's correlation was used for correlation of SHEQ total and subscale scores with DASS total and subscale scores and $p$-value less than 0.05 was considered statistically significant.

\section{RESULTS}

The mean age of participants was $30.12 \pm 7.8$ years. Most of them had spent an average of 4.15 years working and 2 years at the current post. On average, their monthly household income was one hundred and forty-one thousand Pakistani Rupees. Most of the respondents were House Officers (41.9\%), followed by Medical Officers/Postgraduate Trainees (35.9\%), Senior Registrars/Assistant Professors (16.3\%) and Associate/Full Professors (6\%). Most of the respondents were married (51.2\%). Sample from public and private hospitals was approximately $50 \%$ from each type of hospital (Table 1). The mean total SHEQ score of the participants was $48.23 \pm 14.84$. The highest mean score was for

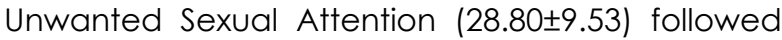
by Gender Harassment (1 1.06 \pm 3.84$)$. The least mean score was of Sexual Coercion (8.37 \pm 2.75$)$.

Table 1: Comparison of mean Sexual Harassment Experience Questionnaire (SHEQ) and the Depression, Anxiety and Stress Scale (DASS) subset scores for female doctors stratified for marital status, designation, and hospital type.

\begin{tabular}{|c|c|c|c|c|c|c|c|c|c|}
\hline \multirow[b]{2}{*}{ Variables } & \multirow[b]{2}{*}{$\mathrm{N}(\%)$} & \multicolumn{4}{|c|}{ Mean SHEQ Scores } & \multicolumn{4}{|c|}{ Mean DASS Scores } \\
\hline & & $\begin{array}{c}\text { Gender } \\
\text { Harassment }\end{array}$ & $\begin{array}{l}\text { Unwanted } \\
\text { Sexual } \\
\text { Attention }\end{array}$ & $\begin{array}{c}\text { Sexual } \\
\text { Coercion }\end{array}$ & SHEQ Total & Depression & Anxiety & Stress & DASS Total \\
\hline \multicolumn{10}{|c|}{ Marital Status } \\
\hline Unmarried & $\begin{array}{c}143 \\
(47.5) \\
\end{array}$ & $12.24 \pm 3.83$ & $31.81 \pm 10.64$ & $8.87 \pm 33.33$ & $52.83 \pm 16.25$ & $11.85 \pm 11.23$ & $8.73 \pm 7.81$ & $15.44 \pm 11.25$ & $33.99 \pm 28.11$ \\
\hline Married & $\begin{array}{c}154 \\
(51.2)\end{array}$ & $9.96 \pm 3.55$ & $26.02 \pm 7.51$ & $8.02 \pm 2.05$ & $44 \pm 12.16$ & $8.83 \pm 9.93$ & $6.66 \pm 7.52$ & $13.30 \pm 10.08$ & $28.05 \pm 25.66$ \\
\hline Divorced & $1(0.3)$ & $15 \pm 0$ & $26 \pm 0$ & $9 \pm 0$ & $50 \pm 0$ & $20 \pm 0$ & $16 \pm 0$ & $32 \pm 0$ & $64 \pm 0$ \\
\hline Widowed & $3(1)$ & $9.33 \pm 1.15$ & $29 \pm 6.92$ & $7 \pm 0$ & $45.33 \pm 8.08$ & $14.67 \pm 9.23$ & $3.33 \pm 1.15$ & $19.33 \pm 11.54$ & $30.67 \pm 19.63$ \\
\hline$p$-Value & & $0.001^{*}$ & $0.001^{*}$ & 0.093 & $0.001^{*}$ & 0.063 & 0.058 & 0.098 & 0.163 \\
\hline \multicolumn{10}{|c|}{ Designation } \\
\hline $\begin{array}{l}\text { House } \\
\text { Officer }\end{array}$ & $\begin{array}{c}126 \\
(41.9) \\
\end{array}$ & $12.21 \pm 3.89$ & $31.49 \pm 10.45$ & $8.79 \pm 3.22$ & $52.49 \pm 15.92$ & $11.9 \pm 10.33$ & $8.84 \pm 7.63$ & $15.17 \pm 11.22$ & $33.99 \pm 27.65$ \\
\hline $\begin{array}{l}\text { Medical } \\
\text { Officers/ } \\
\text { Post } \\
\text { Graduate } \\
\text { Trainee } \\
\end{array}$ & $\begin{array}{c}108 \\
(35.9)\end{array}$ & $10.61 \pm 3.80$ & $28.57 \pm 9.42$ & $8.49 \pm 2.78$ & $47.68 \pm 14.96$ & $10.33 \pm 11.17$ & $7.76 \pm 8.10$ & $14.72 \pm 10.45$ & $31.43 \pm 27.73$ \\
\hline $\begin{array}{l}\text { Senior } \\
\text { Registrar/ } \\
\text { Assistant } \\
\text { Professor }\end{array}$ & $\begin{array}{c}49 \\
(16.3)\end{array}$ & $9.98 \pm 3.50$ & $24.53 \pm 5.47$ & $7.49 \pm 1.16$ & $42 \pm 9.25$ & $8.16 \pm 8.15$ & $6.24 \pm 7.25$ & $13.39 \pm 10.68$ & $27.45 \pm 24.76$ \\
\hline $\begin{array}{l}\text { Associate } \\
\text { Professor/ } \\
\text { Full } \\
\text { Professor }\end{array}$ & $18(6)$ & $8.61 \pm 2.03$ & $22.94 \pm 3.89$ & $7.11 \pm 0.45$ & $38.67 \pm 5.29$ & $5.67 \pm 7.61$ & $2.33 \pm 3.08$ & $10.44 \pm 8.36$ & $17.39 \pm 17.28$ \\
\hline$p$-Value & & $0.001^{*}$ & $0.001^{*}$ & $0.007^{*}$ & 0.0010 & $0.041^{*}$ & $0.004^{*}$ & 0.305 & $0.007^{*}$ \\
\hline \multicolumn{10}{|c|}{ Hospital Type } \\
\hline Private & $\begin{array}{c}144 \\
(47.8) \\
\end{array}$ & $10.78 \pm 3.59$ & $27.79 \pm 9.06$ & $7.92 \pm 1.89$ & $46.49 \pm 13.21$ & $10.15 \pm 10.64$ & $7.29 \pm 7.51$ & $14.39 \pm 10.54$ & $30.98 \pm 27.00$ \\
\hline Public & $\begin{array}{c}157 \\
(52.2)\end{array}$ & $11.31 \pm 4.07$ & $29.73 \pm 9.90$ & $8.79 \pm 3.32$ & $49.82 \pm 16.06$ & $10.55 \pm 10.68$ & $7.96 \pm 7.88$ & $14.48 \pm 10.93$ & $31.04 \pm 26.96$ \\
\hline \multicolumn{2}{|l|}{$p$-Value } & 0.087 & $0.039 *$ & $0.001^{*}$ & $0.015^{*}$ & 0.728 & 0.511 & 0.939 & 0.760 \\
\hline Total & $\begin{array}{c}301 \\
(100) \\
\end{array}$ & $11.06 \pm 3.85$ & $28.80 \pm 9.54$ & $8.37 \pm 2.76$ & $48.23 \pm 14.84$ & $10.36 \pm 10.65$ & $7.64 \pm 7.70$ & $14.44 \pm 10.72$ & $31.01 \pm 26.92$ \\
\hline
\end{tabular}

*Stastistically significant.

The total mean DASS score reported by our participants was $31 \pm 26.92$. Stress was reported as the highest factor (mean score 14.44) followed by
Depression (mean score 10.36). Anxiety was reported as the least (mean score 7.64) by participants of this study (Table 1). 
Table 2: Correlation of Depression, Anxiety and Stress Scale (DASS) and Sexual Harassment Experience Questionnaire (SHEQ) subset scores.

\begin{tabular}{|l|c|c|c|c|}
\hline Variables & Gender Harassment & Unwanted Sexual Attention & Sexual Coercion & Total SHEQ \\
\hline Depression & $0.434^{* * *}$ & $0.385^{* * *}$ & $0.277^{* * *}$ & $0.411^{* * *}$ \\
\hline Anxiety & $0.451^{* * *}$ & $0.481^{* * *}$ & $0.440^{* * *}$ & $0.508^{* * *}$ \\
\hline Stress & $0.388^{* * *}$ & $0.359^{* * *}$ & $0.188^{* *}$ & $0.366^{* * *}$ \\
\hline Total DASS & $0.462^{* * *}$ & $0.450^{* * *}$ & $0.334^{* * *}$ & $0.471^{* * *}$ \\
\hline
\end{tabular}

*** $p<0.001 \quad{ }^{* *} p<0.01$

There was a significant positive correlation between SHEQ total and subscale (Gender Harassment, Unwanted Sexual Attention and Sexual Coercion) and DASS total and subscale scores (Depression, Anxiety and Stress) (Table 2 and Figure 1).

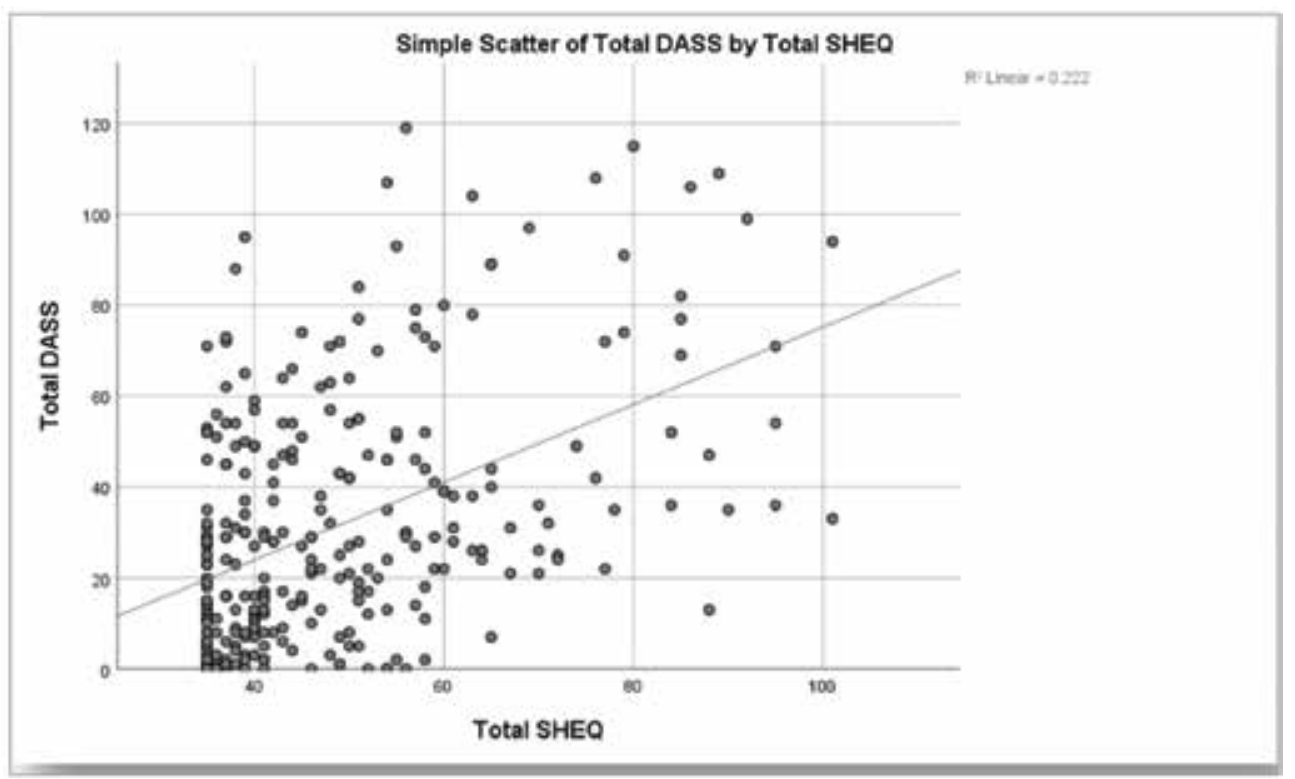

Figure 1: Scatter plot of total Sexual Harassment Experience Questionnaire (SHEQ) by total Depression, Anxiety and Stress Scale (DASS) scores.

\section{DISCUSSION}

Workplace sexual harassment is an unfortunate occurrence. Sadly, health care workers, female doctors and nurses experience sexual harassment, including physical and verbal sexual assault mostly at the hands of male physicians, be they colleagues or superiors ${ }^{16}$. The study observed that younger female doctors experience greater sexual harassment, compared to older doctors. This was consistent with international studies which show a greater prevalence of sexual harassment among young nurses ${ }^{17}$.

Unmarried females also encountered more harassment than married ones. In a Bangladeshi study, it was reported a greater incidence of sexual violence against unmarried women and divorcees as compared to married women ${ }^{18}$. In a hierarchal setting, sexual harassment is more common in junior doctors ${ }^{19}$. This is consistent with the study findings, as it was also conducted in hierarchal setups, and junior doctors had higher scores on the SHEQ than senior doctors.
According to the current study, monthly household income levels did not seem to affect the experiences of these women. However, studies from India and Bangladesh showed that in general, financial dependence left women vulnerable to all sorts of abuse, including sexual harassment and assault ${ }^{20}$. This contrast may be explained by the fact that this study population was doctors who were earning, hence were less vulnerable to abuse in the domestic settings but were still vulnerable at the workplace. Most of the female doctors in the present study reported being stressed because of their job followed by personal life and home-related issues. This is consistent with a study from Iraq, which reported that job stress and burnout are greater in female doctors as compared to males ${ }^{21}$. One reason for this may be verbal and non-verbal sexual harassment which is something male doctors face to a much lesser extent than female doctors 22 .

Internationally, workplace harassment including sexual harassment has been identified as a risk factor for the development of anxiety, sleep distur- 
bance and even suicide ideation ${ }^{23}$. Stress and burnout are also seen in healthcare workers, such as nurses, as a result of sexual harassment ${ }^{24}$. These findings are consistent with our study. Sexual harassment at the workplace, particularly that perpetrated by colleagues is also associated to a significant degree with depression ${ }^{25}$.

Due to the patriarchal society that we live in, such incidents often go unreported ${ }^{24}$. In Pakistan, though studies are available on sexual harassment in nurses, scant data is available regarding the incidence of sexual harassment in female doctors and its impact on their mental health. A study like this study compared the SHEQ scores of nurses with their DASS scores which showed that sexual harassment in nurses positively correlated to depression, anxiety, and stress in these nurses. Hospitals should develop policies to protect female healthcare workers including doctors. Complaint cells should be developed where females can report incidences of verbal, non-verbal and physical harassment. Strict punishments should be meted out to the perpetrators.

The strengths of this study included generalisability and the fact that very few similar studies exist in our country. However, limitations include minimal bias, which cannot be eliminated, though steps had been taken to minimize it, and potential confounders including personality traits that may lead to increased depression, anxiety, and stress, even in the absence of sexual harassment.

\section{CONCLUSION}

Doctors who experience sexual harassment reportedly had a higher degree of depression, anxiety, and stress. In the light of recent happenings in Pakistan as well as abroad, sexual harassment is an issue of paramount importance, to which unfortunately female healthcare workers are quite vulnerable. Thus, the way forward is to conduct studies using the Sexual Harassment Experience Questionnaire in hospitals all over the country, to assess the prevalence of workplace sexual harassment of female doctors.

\section{ACKNOWLEDGEMENTS}

The authors would like to acknowledge the institutions for facilitating the research.

\section{CONFLICT OF INTEREST}

The authors declare no conflict of interest.

\section{ETHICS APPROVAL}

Ethical approval was obtained from the IRB of Al-Shifa School of Public Health, as well the IRB of Rawalpindi Medical University.

\section{PARTICIPANTCONSENT}

Informed consent was taken from each respondent before filling the questionnaire.

\section{AUTHORS' CONTRIBUTION}

FARM was the primary investigator and played the lead role in the conception, designing, planning of the study, data collections entry, analysis, interpretation, and manuscript writing. HS was a major contributor in the designing and planning of the study, data analysis, interpretation, and critical reviewing. AMM conducted the study, data analysis, and interpretation. ABK played an important role in the proceeding of the study and critical review of the manuscript. NK helped with data collection, data entry and analysis. AR helped with data collection, data entry, interpretation of key findings and manuscript writing.

\section{REFERENCES}

1. Sexual Harassment | Definition of Sexual Harassment by Oxford Dictionary on Lexico.com also meaning of Sexual Harassment [Internet]. [cited 2020 Nov 29]. Available from: https://www.lexico.com/definition/sexual_harassment

2. Pakistan Penal Code (Amendment) Bill [Internet]. Ministry of Law and Justice, Government of Pakistan. 2019 [cited 2020 Nov 25]. Available from: http://www.senate.gov.pk/1 web/ordinance/ordVlof2019.pdf

3. Mushtaq M, Sultana S, Imtiaz I. The trauma of sexual harassment and its mental health consequences among nurses. J Coll Physicians Surg Pak. 2015;25(9):675-679.

4. Jafree SR. Workplace violence against women nurses working in two public sector hospitals of Lahore, Pakistan. Nurs Outlook. 2017;65(4):420-427. doi: 10.1016/j.outlook.2017.01.008

5. Malik S. Relationship between workplace harassment and posttraumatic stress symptoms among Pakistani female healthcare professionals (Doctoral dissertation, University of the Punjab Lahore, Pakistan). Available from: http://173.208.131.244:9060/xmlui/handle/123456789/6383

6. Muazzam A, Qayyum F, Cheng J. Experiences of sexual harassment: Interplay of working environment, depression and self-esteem in Pakistani women. Pak J Soc Clin Psychol. 2016;14(1):42-46.

7. Yasmin N, Jabeen S. Workplace harassment: Psychological effects and coping strategies in public and private organizations of Lahore-Pakistan. FWU J Soc Sci. 2017; 11 (1): 310-321.

8. Johnston DA, Harvey SB, Glozier N, Calvo RA, Christensen $H$, Deady $M$. The relationship between depression symptoms, absenteeism and presenteeism. J Affect Disord. 2019;256:536-540. doi: 10.1016/j.jad.2019.06.041

9. Minkina N. Can\# MeToo abolish sexual harassment and discrimination in medicine? Lancet. 2019;394(10196):383-384. doi: 10.1016/S0140-6736 
(19)31731-3

10. Stone L, Phillips C, Douglas KA. Sexual assault and harassment of doctors, by doctors: a qualitative study. Med Educ. 2019;53(8):833-843.doi: 10.1111/medu.13912

11. Bahji A, Altomare J. Prevalence of intimidation, harassment, and discrimination among resident physicians: a systematic review and meta-analysis. Can Med Educ J. 2020; 11(1): 97-123.doi: 10.36834/cmej.57019

12. Llewellyn A, Karageorge A, Nash L, Li W, Neven D. Bullying and sexual harassment of junior doctors in New South Wales, Australia: rate and reporting outcomes. Aust Health Rev. 2018;43(3):328-334. doi: 10.1071/AH17224

13. Baqi S, Albalbeesi A, Iftikhar S, Baig-Ansari N, Alanazi $M$, Alanazi A. Perceptions of gender equality, work environment, support and social issues for women doctors at a university hospital in Riyadh, Kingdom of Saudi Arabia. PloS one. 2017;12(10):1-18. doi: 10.1371/journal.pone.0186896

14. World Health Organization. WHO: Global Atlas of the Health Workforce [Internet] 2020. Available from: https://www.who.int/workforcealliance/knowledge/resources/hrhglobalatlas/en/

15. Raza FA. Reasons for the lack of women's participation in Pakistan's workforce. J Middle East Women's Stud. 2007:3(3):99-102. doi: 10.2979/mew.2007.3.3.99

16. Hussain H, Rehman IU, Bashir S, Begum M, Jehan S. Prevalence and factors associated with harassment in female doctors and nurses in teaching hospitals of KPK. J Gandhara Med Dent Sci. 2019;6(1):9-14. doi: https://doi.org/10.37762/jgmds.6-1.86

17. Houle JN, Staff J, Mortimer JT, Uggen C, Blackstone A. The impact of sexual harassment on depressive symptoms during the early occupational career. Soc Ment Health. 2011;1(2):89-105. doi: $10.1177 / 2156869311416827$

18. Adikaram AS. 'An opportunity for other men and a threat to other women': workplace harassment at the intersection of marital status and gender in Sri Lanka. Hum Resour Dev Int. 2018 ;21 (3):186-21 1. doi: 10.1080/13678868.2017.1413877

19. Toosi NR, Voegeli EN, Antolin A, Babbitt LG, Brown DK. Do Financial literacy training and clarifying pay calculations reduce abuse at work? J Soc Issues. 2020;76(3):681-720. doi: 10.1111/josi.12388

20. Dastan I, Al-Samarraie MA, Jadoo SA. Female doctors are more emotionally exhausted than their male counterparts in Iraq. J Ideas Health. 2019;2(1):75-79. doi: 10.47108/jidhealth.Vol2.Iss 1.18

21. Vargas EA, Brassel ST, Cortina LM, Settles IH, Johnson TR, Jagsi R. \# MedToo: a large-scale examination of the incidence and impact of sexual harassment of physicians and other faculty at an academic medical center. J Women's Health. 2020;29(1):13-20. doi: 10.1089/jwh.2019.7766

22. Hom MA, Stanley IH, Spencer-Thomas S, Joiner TE. Women firefighters and workplace harassment: Associated suicidality and mental health sequelae. J Nerv Ment Dis. 2017;205(12):910-917. doi: 10.1097/NMD.0000000000000759

23. Yang BX, Stone TE, Petrini MA, Morris DL. Incidence, type, related factors, and effect of workplace violence on mental health nurses: a cross-sectional survey. Arch Psychiatr Nurs. 2018;32(1):31-38. doi: 10.1016/j.apnu.2017.09.013

24. Friborg MK, Hansen JV, Aldrich PT, Folker AP, Kjaer $S$, Nielsen $M B$, et al. Workplace sexual harassment and depressive symptoms: a cross-sectional multilevel analysis comparing harassment from clients or customers to harassment from other employees amongst 7603 Danish employees from 1041 organizations. BMC Public Health. 2017;17(1):1-2. doi: 10.1186/s12889-017-4669-x

25. Naveed A, Alwani N. Sexual harassment at work place: are you safe? J Ayub Med Coll. 2010;22(3):222-224. 